\title{
Bone marrow suppression and associated consequences in patients after heart transplantation: A 6-year retrospective review
}

\author{
Michal Pazdernik, Ivan Malek, Eva Koudelkova, Jan Sochman, Josef Kautzner
}

\begin{abstract}
Aims. To evaluate the incidence of bone marrow suppression and consequences of MMF dose adjustment in patients within the first year after heart transplantation.

Methods. Group I $(n=47)$ was treated with a regimen currently used in patients after heart transplantation (mycophenolatemofetil - MMF, valganciclovir - VGC and trimethoprim/sulfamethoxazole - TMP-SMX). Group II ( $n=47)$ received only MMF of potentially myelotoxic medications. The myelotoxic effect and need for dose modification were assessed. The incidence of rejections and infectious episodes associated with MMF adjustment were analyzed during the first 12 months in Group I.

Results. There was a significantly greater proportion of patients with leukopenia (leukocyte count $<4 \times 10 \wedge 9 / L$ ) at 3 months after orthotopic heart transplantation in Group I compared with Group II (19.1\% vs 2.1\%; $P=0.02$ ). The difference in lymphopenia (lymphocyte count $<0.8 \times 10 \wedge 9 / \mathrm{L}$ ) at 3 months follow-up was highly significant (38.3 \% vs $6.4 \%$; $P=0.0002$ ). MMF was modified due to bone marrow suppression or severe infection in $63.8 \%$ patients in Group I and in only $8.5 \%$ of patients in Group II $(P<0.001)$. Reducing or stopping MMF was not associated with increased rejections. In Group I, at least 1 episode of higher degree cellular or humoral rejection occurred in 35\% of patients with the standard MMF dosage compared with only $26 \%$ in patients with modified MMF $(P=0.0534)$.

Conclusions. Addition of VGC+TMP-SMX to current immunosuppressive medication regimen in patients after heart transplantation is associated with significant lymphocytopenia and leukopenia. Importantly, modification of immunosuppressive prophylaxis (reducing or stopping MMF) leads to normalization of blood count without increased incidence of rejections.
\end{abstract}

Key words: heart transplant, medication regimen, myelotoxicity, rejections

Received: December 2, 2014; Accepted with revision: April 22, 2015; Available online: May 14, 2015

http://dx.doi.org/10.5507/bp.2015.022

Department of Cardiology, Institute for Clinical and Experimental Medicine (IKEM), Prague, Czech Republic Corresponding author: Michal Pazdernik, e-mail:Michal.Pazdernik@email.cz

\section{INTRODUCTION}

In the early period after orthotopic heart transplantation (HTx), patients are particularly vulnerable to rejection $^{1}$ and infectious complications ${ }^{2,3}$. Immunosuppressive and anti-infective drug prophylaxis consists of drugs with potentially myelotoxic effects.

Current maintenance immunosuppression is achieved with a combination of different immunosuppressive agents. This generally comprises corticosteroids in combination with calcineurin inhibitors, tacrolimus or cyclosporin, and the antiproliferative agent mycophenolate mofetil (MMF). In addition, current guidelines ${ }^{4}$ recommend dual anti-infective prophylaxis composed of valganciclovir (VGC) and trimethoprim/sulfamethoxazole (TMP-SMX). One of most serious adverse reactions associated with immunosuppressive and anti-infective drug prophylaxis is bone marrow suppression. In this respect, leukopenia ${ }^{5}$ and anemia ${ }^{6}$ are the most frequent consequences.

On the one hand MMF significantly reduces acute rejection rates after heart transplantation ${ }^{7,8}$. But the benefits are often offset by drug intolerance or myelotoxicity ${ }^{9-11}$ that necessitate dose reduction or complete withdrawal. Besides shock and multi-organ dysfunction following the intense inflammatory reaction to sepsis, complications arising from sepsis-related immunoparalysis contribute to morbidity and mortality ${ }^{12,13}$. Hence, adjustment of the MMF dose is also required in patients with severe infection. Data on the clinical consequences of MMF dose reduction are scarce. The goal of this study was to assess the potential myelotoxic effects of MMF, VGC and TMP-SMX after heart transplantation. Second, we evaluated whether MMF dose reduction due to excessive bone marrow suppression or severe infection is associated with subsequent risk of acute rejection.

\section{MATERIALS AND METHODS}

Potential myelotoxic effects of MMF, VGC and TMPSMX after heart transplantation was analyzed retrospectively in a study population from a period spanning 6 years (2004-2009). All patients were in a terminal state of heart failure and underwent orthotopic heart transplant at the Institute for Clinical and Experimental Medicine (IKEM), Prague, Czech Republic. Prophylaxis comprising the above potentially myelotoxic agents was initiated in all patients within one month after the transplantation. 
An internal institutional database was used to identify all patients. The medical records of all 94 adult patients (aged $>18$ years) were subsequently analyzed.

The patient population was divided in two subgroups. Group I, called a "current regimen group" (period between 2008-2009), included 47 patients in whom the immunosuppressive regimen during the first month after the heart transplant consisted of MMF, VGC and TMP-SMX. Group II, entitled the "previous regimen group" (period between 2004 - 2007), also included 47 patients treated with only one potentially myelotoxic agent, MMF (as regular VGC and TMP-SMX administration started in our center in 2008). Patients treated with VGC for cytomegalovirus infection and patients treated with TMP-SMX, respectively, were not included in this group. The dosage of potentially myelotoxic drugs according to our institutional recommendations was as follows: MMF was started at $500 \mathrm{mg}$ i.v. peroperatively, continued by $500 \mathrm{mg}$ i.v. BID on the first day after heart transplant, followed by $1 \mathrm{~g}$ p.o. BID. MMF blood levels were not monitored during the follow-up. VGC as a general prophylaxis was administered in a dose of $900 \mathrm{mg}$ per day and TMP-SMX in a dose of $480 \mathrm{mg}$ per day (TMP $80 \mathrm{mg} / \mathrm{SMX} 400 \mathrm{mg}$ ) and the duration of treatment was 100 and 90 days, respectively. Anti-thymocyte globulin (ATG-Fresenius S.) $1.25 \mathrm{mg} / \mathrm{kg}$ i.v. was used as induction therapy for all patients in the first two days. In the days following, ATG was carefully administered depending on lymphocyte count. In case when optimal lymphocyte count was reached, ATG was administered not any more. Corticosteroids were administered according to inner institutional protocol; all patients in the cohort used at least $5 \mathrm{mg}$ of Prednisone in $12^{\text {th }}$ month after HTx.

The data collected in both patient groups included basic demographics, information on the etiology of heart failure and blood element counts (erythrocytes, leukocytes, neutrophils, lymphocytes, thrombocytes) in selected periods (before heart transplant; 3, 6 and 12 months after heart transplant). The need for dose adjustment or complete withdrawal of MMF due to bone marrow suppression or severe infection was also recorded.

The incidence of graft rejections during the first 12 months after heart transplant in both groups was analyzed. Endomyocardial biopsies were planned and performed according to the institutional protocol. Patients underwent biopsy every week until 30 days post-transplant, and then every 2 weeks for 3 months, followed by once a month for 6 months. The last regular biopsies were scheduled on the 9 th and 12 th month after the heart transplant.

The MMF dose was modified or treatment was terminated depending on all available information such as leukopenia $<4000$ leukocytes $/ \mathrm{mm}^{3}$ and/or severe lymphopenia and in certain cases, of severe infection. In case of blood count normalization, the dose of MMF was either individually enhanced or MMF was reinitiated in lower doses under careful monitoring.

The data are expressed in medians. Both absolute and relative frequencies were used for description. For testing discrete variables, the chi-squared test was applied and for continuous variables the t-test or Mann-Whitney test was used. Bonferroni correction for significance levels was applied in case of multiple testing.

\section{Definitions}

According to the revised (R) ISHLT classification we distinguished three grades of acute rejection: Grade $0 \mathrm{R}$ no rejection (no change from 1990 classification); Grade $1 \mathrm{R}$ - mild rejection (corresponding to 1990 Grades 1A, $1 \mathrm{~B}$ and 2); Grade 2 R-moderate rejection (replacing 1990 Grade 3A); and Grade $3 \mathrm{R}$ - severe rejection (Grades 3B and 4 in 1990 classification). Antibody-mediated rejection after heart transplantation was based on evidence of endothelial injury and antibody and complement deposition.

\section{RESULTS}

A total of 94 patients were identified. There were 47 patients in Group I - Tacrolimus (44 patients) / Cyclosporin ( $n=3$ patients), Prednison, MMF, VGC, TMP-SMX and 47 patients in Group II - Tacrolimus (10 patients) / Cyclosporin (37 patients), Prednison, MMF. No significant differences in patient demographic data and predisposing conditions of heart failure were found between the two groups. Group I consisted of 40 men, median age 53.1 years, proportion of ischemic vs dilated cardiomyopathy $30 / 47 \%$. Group II comprised 36 men, median age 50.5 years, proportion of ischemic vs dilated cardiomyopathy $43 / 43 \%$ (Table 1 ).

A significantly higher proportion of patients with leukopenia (leukocyte count $<4 \times 10^{\wedge} 9 / \mathrm{L}$ ) at three months after orthotopic heart transplantation was found in Group I compared to Group II ( $19.1 \%$ vs $2.1 \%$; $P=$ 0.02 ). Similarly, lymphopenia (lymphocyte count $<0.8$ $\left.\mathrm{x} 10^{\wedge} 9 / \mathrm{L}\right)$ at 3 months of follow up was significantly more frequent in Group I ( $38.3 \%$ vs $6.4 \% ; P=0.0002)$. This finding was valid at one year after transplantation $(19.1 \%$ vs $4.3 \%$ Group II; $P=0.05$ ) (Table 2, Fig. 1). There were no major differences in number of other blood elements (erythrocytes, neutrophils) between the two groups in the reference periods ( 1 month, 3 months, 6 months and 12 months after heart transplantation). Thrombocyte count showed a statistically significant difference between groups 3 and 12 months after heart transplant, but this finding was clinically insignificant. 3 patients from Group I developed symptomatic CMV infection after VGC withdrawal during follow-up.

Severe infection was found in $25.5 \%$ (12/47) of patients in Group I - 3 cases of symptomatic CMV infection, 7 cases of pneumonia ( $5 \mathrm{x}$ Aspergillus fumigatus, $1 \mathrm{x}$ Pseudomonas pseudoalcaligenes, $1 \mathrm{x}$ Candida albicans) and 2 cases of sepsis (Staphylococcus aureus, Klebsiella pneumonie). Compared to Group II where severe infections were noted in $12.8 \%$ (6/47) - Klebsiella oxytoca sepsis ( 2 cases), Burkholderia cepacia pneumonia (1 case), Toxoplasma gondii myocarditis (1 case), Staphylococcus coagulase negative+Corynebacterium species mediasti- 
Table 1. Patient characteristics data.

\begin{tabular}{lcccc}
\hline & Anti-Infective prophylaxis & Number of men/women & Median age & Ischemic/Dilated cardiomyopathy \\
\hline Group I $(\mathrm{n}=47)$ & VGC + TMP-SMX & $40 / 7$ & 53.1 years & $30 / 47 \%$ \\
Group II $(\mathrm{n}=47)$ & - & $36 / 11$ & 50.5 years & $43 / 43 \%$ \\
\hline
\end{tabular}

VGC - valganciclovir, TMP-SMX - trimethoprim/sulfamethoxazole

Table 2. Percentage of patients who developed significant bone marrow suppression during follow up.

\begin{tabular}{|c|c|c|c|c|c|c|c|c|}
\hline Count & $\begin{array}{c}\text { "Current" } \\
\text { regimen } \\
\text { D0 } \\
(\%) \\
\end{array}$ & $\begin{array}{c}\text { "Previous" } \\
\text { regimen } \\
\text { D0 } \\
(\%) \\
\end{array}$ & $\begin{array}{l}\text { "Current" } \\
\text { regimen } \\
\text { M1 } \\
(\%)\end{array}$ & $\begin{array}{c}\text { "Previous" } \\
\text { regimen } \\
\text { M1 } \\
(\%)\end{array}$ & $\begin{array}{l}\text { "Current" } \\
\text { regimen } \\
\text { M3 } \\
(\%) \\
\end{array}$ & $\begin{array}{c}\text { "Previous" } \\
\text { regimen } \\
\text { M3 } \\
(\%)\end{array}$ & $\begin{array}{c}\text { "Current" } \\
\text { regimen } \\
\text { M12 } \\
(\%)\end{array}$ & $\begin{array}{l}\text { "Previous" } \\
\text { regimen } \\
\text { M12 } \\
(\%)\end{array}$ \\
\hline \multicolumn{9}{|l|}{ Erythrocyte } \\
\hline \multirow[t]{2}{*}{$<4 \times 10^{12} / \mathrm{L}$} & 31.9 & 51.1 & 83 & 70.2 & 40.4 & 23.4 & 14.9 & 23.4 \\
\hline & \multicolumn{2}{|c|}{$P=0.06$} & \multicolumn{2}{|c|}{$P=0.14$} & \multicolumn{2}{|c|}{$P=0.08$} & \multicolumn{2}{|c|}{$P=0.29$} \\
\hline \multicolumn{9}{|l|}{ Thrombocyte } \\
\hline \multirow[t]{2}{*}{$<130 \times 10^{9} / \mathrm{L}$} & 0 & 2.1 & 4.3 & 2.1 & 4.3 & 0 & 12.8 & 0 \\
\hline & \multicolumn{2}{|c|}{$P=1$} & \multicolumn{2}{|c|}{$P=1$} & \multicolumn{2}{|c|}{$P=0.48$} & \multicolumn{2}{|c|}{$P=0.09$} \\
\hline \multicolumn{9}{|l|}{ Neutrophil } \\
\hline \multirow[t]{2}{*}{$<2 \times 10^{9} / \mathrm{L}$} & 2.1 & 2.1 & 0 & 0 & 6.4 & 2.1 & 0 & 6.4 \\
\hline & \multicolumn{2}{|c|}{$P=1$} & \multicolumn{2}{|l|}{-} & \multicolumn{2}{|c|}{$P=0.61$} & \multicolumn{2}{|c|}{$P=0.24$} \\
\hline \multicolumn{9}{|l|}{ Leucocyte } \\
\hline \multirow[t]{2}{*}{$<4 \times 10^{9} / \mathrm{L}$} & 6.4 & 2.1 & 2.1 & 2.1 & 19.1 & 2.1 & 4.3 & 6.4 \\
\hline & \multicolumn{2}{|c|}{$P=0.61$} & \multicolumn{2}{|c|}{$P=1$} & \multicolumn{2}{|c|}{$P=0.02$} & \multicolumn{2}{|c|}{$P=1$} \\
\hline \multicolumn{9}{|l|}{ Lymphocyte } \\
\hline \multirow[t]{2}{*}{$<0.8 \times 10^{9} / \mathrm{L}$} & 2.1 & 6.4 & 53.2 & 34 & 38.3 & 6.4 & 19.1 & 4.3 \\
\hline & \multicolumn{2}{|c|}{$P=0.61$} & \multicolumn{2}{|c|}{$P=0.06$} & \multicolumn{2}{|c|}{$P=0.0002$} & \multicolumn{2}{|c|}{$P=0.05$} \\
\hline
\end{tabular}

D0 - before HTx, M1 - 1 month after HTx, M3 - 3 months after HTx, M12 - 12 months after HTx

Table 3. Association of severe infections with MMF dose adjustment.

\begin{tabular}{llll}
\hline & $\begin{array}{l}\text { Number of severe } \\
\text { infections }\end{array}$ & $\begin{array}{l}\text { Number of patients with MMF dose } \\
\text { adjustment independent on severe } \\
\text { infection }\end{array}$ & $\begin{array}{l}\text { Number of patients with MMF dose } \\
\text { adjustment due to severe infection }\end{array}$ \\
\hline "Current" regimen $(\mathrm{n}=47)$ & $12 / 47(25.5 \%)$ & 5 & 7 \\
"Previous" regimen $(\mathrm{n}=47)$ & $6 / 47(12.8 \%)$ & 3 & 1 \\
\hline
\end{tabular}

MMF- mycophenolate mofetil

Table 4. Distribution of rejections in both regimens.

\begin{tabular}{lccccc}
\hline & $\begin{array}{c}\text { No } \\
\text { rejections }\end{array}$ & $\begin{array}{c}1 \mathrm{R} / 1 \mathrm{~A} \\
\text { rejections }\end{array}$ & $\begin{array}{c}1 \mathrm{R} / 2 \text { and higher } \\
\text { rejections }\end{array}$ & $\begin{array}{c}\text { Humoral } \\
\text { rejections }\end{array}$ & $\begin{array}{c}\text { Humoral+cellular } \\
\text { rejections }\end{array}$ \\
\hline "Current" regimen $(\mathrm{n}=47)$ & 8 & 25 & 11 & 2 & 1 \\
"Previous"regimen $(\mathrm{n}=47)$ & 4 & 17 & 16 & 2 & 2 \\
\hline
\end{tabular}

nitis ( 1 case) and Pseudomonas aeruginosa pneumonia (1 case). MMF was reduced or discontinued in $63.8 \%$ (30/47) of patients in Group I, while only 8.5\% (4/47) of patients in Group II required the same adjustment $(P$ $<0.001)$. The proportion of patients with withdrawal vs reduced dose of MMF was 22/8 in Group I, compared to $2 / 2$ in Group II. The main reason for MMF dose adjustment was bone marrow suppression - in $44.7 \%$ $(21 / 47)$ patients in Group I and in 6.4\% (3/47) patients in Group II. MMF dose was adjusted during severe infection in 7 patients in Group I and in 1 patient in Group II (Table 3). In addition to regulation of MMF dosage,
VGC had to be temporarily withdrawn in $14.9 \%$ (7/47) of patients in Group I due to inadequate compensation of blood count. Agranulocytosis requiring administration of G-CSF (Filgrastim) was reported in 6.38\% (3/47) patients in Group I. Administration of MMF had to be modified due to gastrointestinal toxicity in addition to $4.3 \%(2 / 47)$ of patients in Group I. No gastrointestinal intolerance in relation to MMF administration was found in Group II.

The number of patients with at least one episode of graft rejection ( $n=94$ ) within 12 months after index procedure in Group I versus Group II had the following values: without rejection $(8 / 4), 1 \mathrm{R} / 1 \mathrm{~A}$ rejection $(25 / 17), 1 \mathrm{R} / 2$ 
Erythrocyte count

(4-6 x10^12/L)

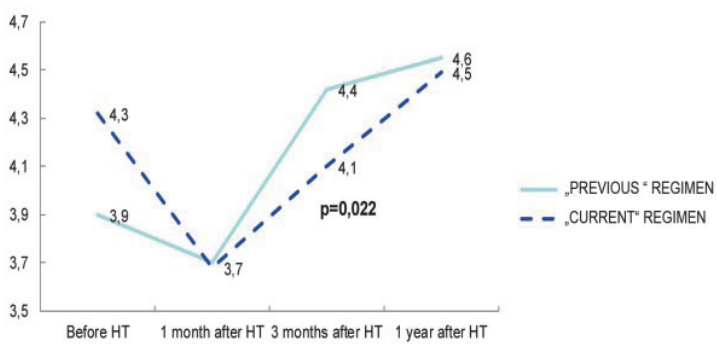

Neutrophil count

$\left(2-7.8 \times 10^{\wedge} \mathrm{g} / \mathrm{L}\right)$

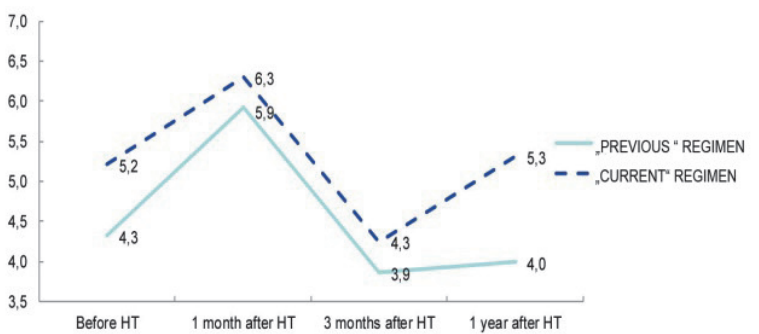

Thrombocyte count

$\left(130-400 \times 10^{\wedge} 9 / L\right)$

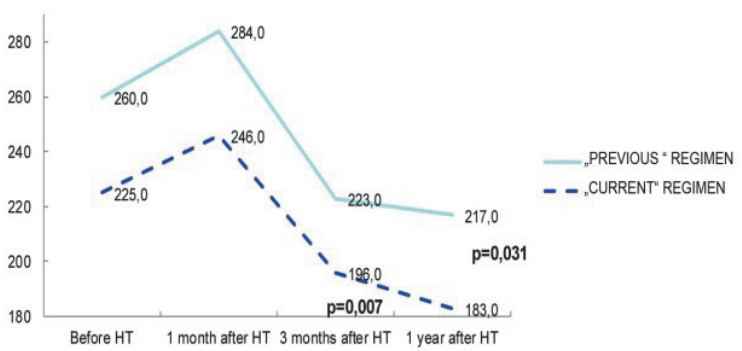

Leucocyte count

$\left(4-10 \times 10^{\wedge} 9 / L\right)$

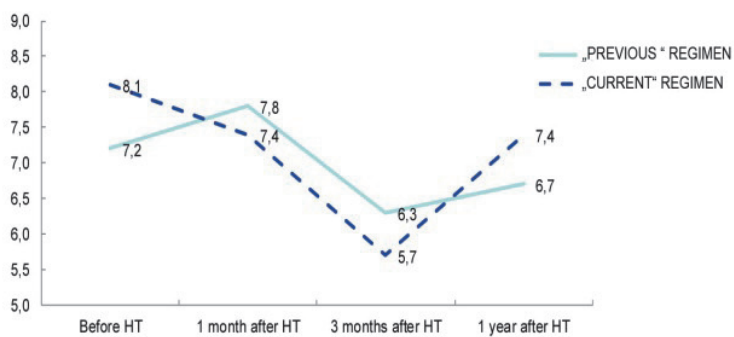

Lymphocyte count

$\left(0.8-4 \times 10^{\wedge} \mathrm{g} / \mathrm{L}\right)$

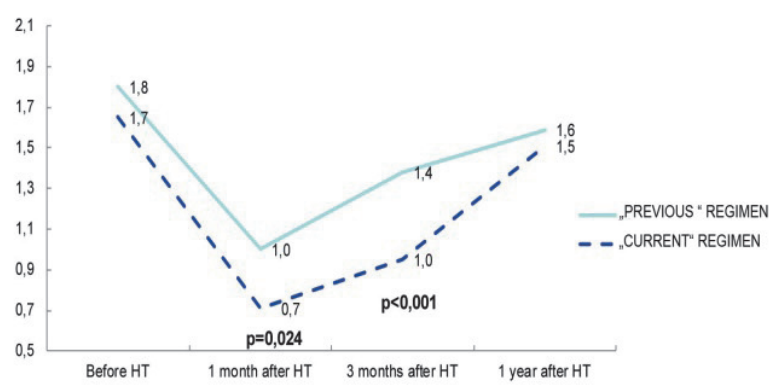

Fig. 1. Comparison of both regimens in terms of myelotoxicity (number of blood elements in reference periods).

and higher rejection $(11 / 22)$, humoral rejection $(2 / 2)$, humoral + cellular rejection $(1 / 2)$ (Table 4$)$.

Interestingly, modification of immunosuppressive therapy was not associated with increased incidence of rejections. At least 1 episode of higher degree cellular or humoral rejection occurred in Group I in 35\% (6/17) of patients with the standard MMF dosage compared with only $26 \%(8 / 30)$ occurrence rate in patients with dose reduction or complete withdrawal of MMF $(P=0.0534)$.

\section{DISCUSSION}

Data are scarce on the clinical impact of different immunosuppressive regimens used in cardiac transplant care on bone marrow suppression. Clinicians are compelled to choose between interim ignoring low WBC count, adjusting the MMF/VGC dose or using G-CSF. Moreover severe infections require adjustment of the patient's immunosuppressive regimen after heart transplantation. This therapy modification increases the risk of graft rejection.

Infection remains a major cause of morbidity and mortality following transplantation ${ }^{14,15}$, but antimicrobial prophylaxis regimens continue to improve. The most recommended prophylactic antimicrobial therapy consists of VCG and TMP-SMX. Although these drugs decrease the risk of infectious complications, they may increase the myelotoxic effects of immunosuppressives. Since 2008, both VGC and TMP-SMX have been added to immunosuppressive regimen of all patients undergoing heart transplant at our institution. In this study, we found that "the current medication regimen" (including VGC+ TMP-SMX) causes more pronounced bone marrow suppression than the "previous medication regimen". A significant proportion of patients on current medication had lymphopenia and leukopenia. No other blood 
elements were significantly/clinically affected. Brum et al. ${ }^{16}$ reported more pronounced leukopenia in patients with concomitant administration of MMF and VGC. The risk factors associated with VGC-induced leukopenia were not clear. Chen et al. ${ }^{17}$ demonstrated that VGC toxicity was related to low body mass index, suggesting that dose should be adjusted to body weight, and racial and genetic factors may be important.

Although MMF significantly decreases acute rejection rates after heart transplantation, dose reduction or complete withdrawal due to intolerance or toxicity is necessary relatively often. The rate of MMF dose reduction because of side effects ranges from $42 \%$ to $53 \%$ (ref. ${ }^{9-11}$ ). We report markedly higher incidence of medication modification in the "current regimen" group. The reason for this significant difference was pronounced bone marrow suppression and the presence of more episodes of severe infections that forced us to adjust the dose or completely discontinue MMF in the "current regimen" group. We assume that the "current regimen" group with its more pronounced bone marrow suppression effect increases the patient's susceptibility to infections. A surprisingly low incidence of gastro-intestinal side effects related to MMF administration was found in our cohort.

The consequences of MMF dose reduction or complete withdrawal have not been clearly established. Some evidence suggests that MMF dose modification, either reduction or discontinuation, may increase rejection rate and graft loss. However, studies investigating this relationship are mainly related to renal transplants ${ }^{18-20}$, while data from cardiac transplant registries are scarce ${ }^{21-22}$. Knoll et al. ${ }^{18}$ found that the cumulative number of days on reduced MMF dose increased significantly the risk of acute graft rejection. In contrast, Khosroshahi et al. ${ }^{23}$ showed that MMF dose reduction was not associated with an increased risk of acute allograft rejection or impaired allograft function at 5 years.

In our study population, we modified or completely withdrew MMF from therapy in $63.8 \%$ of patients in the "current regimen" group and only in $8.5 \%$ patients in the "previous regimen" group. Importantly, modification of immunosuppressive therapy in Group I was not associated with increased incidence of rejections $(P=0.0534)$. These findings are consistent with the results of the TICTAC trial $^{24}$ which showed that addition of MMF to single-agent immunosuppression does not provide any advantage over single-agent immunosuppression in terms of rejections. Similar results were also found by Teuteberg ${ }^{25}$ who reported a regimen consisting of a dose reduced MMF in patient after HTx.

There are several possible explanations for these findings. First, addition of VGC to therapy is likely to decrease the incidence of CMV infections that have been associated with indirect adverse effects such as increased incidence of acute graft rejections ${ }^{26-28}$. Second, although it is generally known that both MMF and VGC are eliminated by renal excretion, no convincing data are available on potential pharmacokinetic interaction between both drugs. VGC could potentially increase the level of MMF in patients with lowered dose of the drug. Only limited information exists on concomitant administration of MMF and VGC (ref. ${ }^{29,30}$ ). Third, VGC itself can act as immunosuppressive agent in patients on a modified regimen of MMF. In this respect, pilot data suggest that VGC suppresses lymphocyte proliferation and activation in patients after renal transplantation ${ }^{31}$.

Our report demonstrates that reducing or stopping MMF leads to normalization of blood count without increased incidence of rejections. We consider this approach a potentially safe method for managing with the myelotoxic effects of current medication regimen after HTx.

\section{Study limitations}

The study has the following limitations: First, the retrospective nature of case identification. For this reason, data acquisition did not allow for the complete collection of patient information. Second, the sample size is relatively small. However, the two groups of patients were managed by the same team and the only differences were in prophylactic regimen. Third, no monitoring of MMF in blood was available during follow-up. Fourth, detailed monitoring of ATG and corticosteroids doses was not performed during the post-transplant period.

\section{CONCLUSIONS}

Contemporary immunosuppressive and anti-infective drug prophylaxis is associated with significant lymphocytopenia and leukopenia. In case of a profound druginduced myelotoxicity, reducing or stopping MMF leads to normalization of blood count and does not inflict increased incidence of rejection episodes.

\section{ACKNOWLEDGEMENT}

We would like to thank Vera Lanska for help with statistical analysis.

Author contributions: MP, IM: research, manuscript writing; EK, JS, JK: manuscript writing.

Conflict of interest statement: The authors state that there are no conflicts of interest regarding the publication of this article.

\section{REFERENCES}

1 Delgado JF, Sánchez V, de la Calzada CS. Acute rejection after heart transplantation. Expert Opin Pharmacother 2006;7(9):1139-49.

2 Gurguí M, Muñoz P. [Infection in heart transplantation]. Enferm Infecc Microbiol Clin 2007;25(9):587-597; quiz 598.

3 Montoya JG, Giraldo LF, Efron B, Stinson EB, Gamberg P, Hunt S, Giannetti N, Miller J, Remington JS. Infectious complications among 620 consecutive heart transplant patients at Stanford University Medical Center. Clin Infect Dis 2001;33(5):629-40.

4 Costanzo MR, Dipchand A, Starling R, Anderson A, Chan M, Desai S, Fedson S, Fisher P, Gonzales-Stawinski G, Martinelli L, McGiffin D, Smith J, Taylor D, Meiser B, Webber S, Baran D, Carboni M, Dengler T, Feldman D, Frigerio M, Kfoury A, Kim D, Kobashigawa J, Shullo M, Stehlik J, Teuteberg J, Uber P, Zuckermann A, Hunt S, Burch M, Bhat G, Canter C, Chinnock R, Crespo-Leiro M, Delgado R, Dobbels 
F, Grady K, Kao W, Lamour J, Parry G, Patel J, Pini D, Towbin J, Wolfel G, Delgado D, Eisen H, Goldberg L, Hosenpud J, Johnson M, Keogh A, Lewis C, O'Connell J, Rogers J, Ross H, Russell S, Vanhaecke J. The International Society of Heart and Lung Transplantation Guidelines for the care of heart transplant recipients. J Heart Lung Transplant 2010;29(8):914-56.

5 Roth D, Colona J, Burke GW, Ciancio G, Esquenazi V, Miller J. Primary immunosuppression with tacrolimus and mycophenolate mofetil for renal allograft recipients. Transplantation 1998;65(2):248-52.

6 Blosser CD, Bloom RD. Posttransplant anemia in solid organ recipients. Transplant Rev (Orlando) 2010;24(2):89-98.

7 Kobashigawa J, Miller L, Renlund D, Mentzer R, Alderman E, Bourge R, Costanzo M, Eisen H, Dureau G, Ratkovec R, Hummel M, Ipe D, Johnson J, Keogh A, Mamelok R, Mancini D, Smart F, Valantine H, The Mycophenolate Mofetil Investigators. A randomized active-controlled trial of mycophenolate mofetil in heart transplant recipients. Transplantation 1998;66(4):507-15.

8 Eisen H, Kobashigawa J, Keogh A, Bourge R, Renlund D, Mentzer $\mathrm{R}$, Alderman $\mathrm{E}$, Valantine $\mathrm{H}$, Dureau G, Mancini D, Mamelok R, Gordon R, Wang W, Mehra M, Constanzo MR, Hummel M, Johnson J; Mycophenolate Mofetil Cardiac Study Investigators. Three year results of a randomized, double blind, controlled trial of mycophenolate mofetil versus azathioprine in cardiac transplant recipients. J Heart Lung Transplant 2005;24(5):517-25.

9 Squifflet JP, Backman L, Claesson K, Dietl KH, Ekberg H, Forsythe JL, Kunzendorf U, Heemann U, Land W, Morales JM, Mühlbacher F, Talbot D, Taube D, Tyden G, van Hooff J, Schleibner S, Vanrenterghem Y, European Tacrolimus-MMF Renal Study Group. Dose optimization of mycophenolate mofetil when administered with a low dose of tacrolimus in cadaveric renal transplant recipients. Transplantation 2001;72(1):63-9.

10 Mourad M, Malaise J, Chaib Eddour D, De Meyer M, König J, Schepers R, Squifflet JP, Wallemacq P.Correlation of mycophenolic acid pharmacokinetic parameters with side effects in kidney transplant patients treated with mycophenolate mofetil. Clin Chem 2001;47(1):88-94.

11 Pelletier RP, Akin EB, Bumgardner GL, Rajab A, Elkhammas EA, Henry $\mathrm{ML}$, Ferguson RM. Mycophenolate mofetil dose reduction influences clinical outcome following kidney transplantation. Am J Transplant 2003;2(Suppl 3):467.

12 Sundar KM, Sires M. Sepsis induced immunosuppression Implications for secondary infections and complications. Indian Crit Care Med 2013;17(3):162-9.

13 Muenzer JT, Davis CG, Chang K, Schmidt RE, Dunne WM, Coopersmith CM, Hotchkiss RS. Characterization and modulation of the immunosuppressive phase of sepsis. Infect Immun 2010;78(4):1582-92.

14 Sánchez-Lázaro IJ, Almenar L, Blanes M, Martínez-Dolz L, Portolés $M$, Roselló E, Rivera $M$, Salvador A. Timing, etiology, and location of first infection in first year after heart transplantation. Transplant Proc 2010;42(8):3017-19.

15 Kotton CN, Kumar D, Caliendo AM, Åsberg A, Chou S, Snydman DR, Allen U, Humar A; Transplantation Society International CMV Consensus Group. International consensus guidelines on the management of cytomegalovirus in solid organ transplantation. Transplantation 2010;89(7):779-95.

16 Brum S, Nolasco F, Sousa J, Ferreira A, Possante M, Pinto JR, Barroso $E$, Santos JR. Leucopenia in kidney transplant patients with the association of valganciclovir and mycophenolate mofetil. Transplant Proc 2008;40(3):752-4.

17 Chen I, Chang H, Hsu C, Lai ST, Hsieh YC, Shih CC. Correlation between body mass index and leucopenia after administration of valganciclovir for cytomegalovirus infection in Chinese cardiac recipients. Circ J 2007; 71(6):968-72.

18 Knoll GA, MacDonald I, Khan A, Van Walraven C. Mycophenolate mofetil dose reduction and the risk of acute rejection after renal transplantation. J Am Soc Nephrol 2003;14(9):2381-6.

19 Bunnapradist S, Lentine KL, Burroughs TE, Pinsky BW, Hardinger KL, Brennan DC, Schnitzler MA. Mycophenolate mofetil dose reductions and discontinuations after gastrointestinal complications are associated with renal transplant graft failure. Transplantation 2006:82(1):102-7.

20 Kahu J, Kyllönen L, Salmela K. Impact of mycophenolate mofetil intolerance on early results of kidney transplantation. Transplant Proc 2005;37(8):3276-9.

21 Segovia J, Gerosa G, Almenar L, Livi U, Viganò M, Arizón JM, Yonan N, Di Salvo TG, Renlund DG, Kobashigawa JA; ERL 2401 Study Group. Impact of dose reductions on efficacy outcome in heart transplant patients receiving enteric-coated mycophenolate sodium or mycophenolate mofetil at 12 months post-transplantation. Clin Transplant 2008;22(6):809-14.

22 Galiwango PJ, Delgado DH, Yan R, Kozuszko S, Smith R, Rao V, Ross $\mathrm{HJ}$. Mycophenolate mofetil dose reduction for gastrointestinal intolerance is associated with increased rates of rejection in heart transplant patients. J Heart Lung Transplant 2008;27(1):72-7.

23 Khosroshahi HT, Shoja MM, Peyrovifar A, Hashemi SR, Amjadi M. Mycophenolate Mofetil Dose Reduction in Renal Transplant Recipients: A 5-Year Follow-up Study. Transplant Proc 2009;41(7):2797-9.

24 Baran DA, Zucker MJ, Arroyo LH, Camacho M, Goldschmidt ME, Nicholls SJ, Prevost-Fernandez J, Carr C, Adams L, Pardi S, Hou V, Binetti M, McCahill J, Chichetti J, Viloria V, Sanagustin MG, EbuengaSmith J, Mele L, Martin A, Blicharz D, Wolski K, Olesnicky L, Qian F, Gass AL, Cohen M. A prospective, randomized trial of single-drug versus dual-drug immunosuppression in heart transplantation: the tacrolimus in combination, tacrolimus alone compared (TICTAC) trial. Circ Heart Fail 2011;4(2):129-37.

25 Teuteberg JJ, Shullo MA, Zomak R, Toyoda Y, McNamara DM, Bermudez C, Kormos RL, McCurry KR. Alemtuzumab induction prior to cardiac transplantation with lower intensity maintenance immunosuppression: one-year outcomes. Am JTransplant 2010;10(2):3828.

26 Emery V. Facing the facts: the indirect effects of cytomegalovirus. Transplantation 2007;84(6S):S7-S10.

27 Grattan MT, Moreno-Cabral CE, Starnes VA, Oyer PE, Stinson EB, Shumway NE. Cytomegalovirus infection is associated with cardiac allograft rejection and atherosclerosis. JAMA 1989:261(24):3561-6.

28 Vymetalova J, Kubanek M, Gazdic T, Vrbska J, Malek I, Kautzner J. Comparison of universal prophylaxis and preemptive treatment with valganciclovir in management of cytomegalovirus infection in heart transplant recipients. Cor Vasa 2012;54(1):e16-e21.

29 Molina Perez E, Fernández Castroagudín J, Seijo Ríos S, Mera Calviño J,Tomé Martínez de Rituerto S, Otero Antón E, Bustamante Montalvo $M$, Varo Perez E. Valganciclovir-induced leukopenia in liver transplant recipients: influence of concomitant use of mycophenolate mofetil. Transplant Proc 2009:41(3):1047-9.

30 Rerolle JP, Szelag JC, Le Meur Y. Unexpected rate of severe leucopenia with the association of mycophenolate mofetil and valganciclovir in kidney transplant recipients. Nephrol Dial Transplant 2007;22(2):671-2.

31 Reischig T, Prucha M, Sedlackova L, Lysak D, Jindra P, Bouda M, Matejovic M. Valganciclovir prophylaxis against cytomegalovirus impairs lymfocyte proliferation and activation in renal transplant recipients. Antivir Ther 2011;16(8):1227-35. 